\title{
Calculating Chilling Hours and Chill Units from Daily Maximum and Minimum Temperature Observations
}

\author{
Dale E. Linvill \\ Agricultural Engineering Department, Clemson University, Clemson, SC 29634
}

\begin{abstract}
Models that require hourly weather data as inputs are being constructed to simulate development of insects and plants. Most agricultural and, climatological weather observation stations, however, do not include the capability to record hourly data. Thus, methods, for simulating hourly observations need to be developed if the wealth of data collected in such stations is to be used in these models.

One application for simulated temperature data is in the peach industry. This industry uses chilling hours and chill units to determine progression of fulfillment of chilling requirements through the winter season. In the past, chill hours and chill units have been calculated at a limited number of locations using either manually recorded hourly observations or thermograph charts.
\end{abstract}

Richardson (1974) proposed a very simple model for determining temperatures from which chill units were calculated. He used a straight line with $12 \mathrm{hr}$ between maximum and minimum temperature. Richardson recognized the limitations of this model, especially when assuming the daily temperature curve was symmetrical about $12 \mathrm{hr}$. He suggested that the time between maximum and minimum temperature may need to be changed to better represent daylength changes during the year.

McFarland et al. (1987) compared various mathematical representations of the daily heating wave. In their analysis, most published models used a modified sine function to describe heating during daytime hours. A sine function should be a close representation of the curve because daytime temperatures follow the daily solar cycle.

The nighttime cooling curve, however, is not as simple. Cooling depends on many factors, including moisture content of the air, cloud cover, and soil heat flow. One form of the cooling curve suggested by Sutton (1953) depends on the square root of time since sunset. Parton and Logan (1981) used an exponential cooling rate to describe nighttime cooling. Eckersten (1986) modified Parton and Logan's model to a sine-sine ex-

Received for publication 14 Oct. 1988. Technical Contribution no. 2876, South Carolina Agricultural Experiment Station, Clemson Univ., Clemson, S.C. Mention of a trade name does not constitute an endorsement of the product by Clemson Univ. The cost of publishing this paper was defrayed in part by the payment of page charges. Under postal regulations, this paper therefore must be hereby marked advertisement solely to indicate this fact. ponential model that showed improvement in representation of the cooling curve from maximum to minimum temperatures. McCann (1985) used a sine-sine-sine model to represent the heating and cooling curves. Linvill (1982) used a logarithmic nighttime cooling curve.

\section{MODEL DEVELOPMENT}

In each of the above models, an underlying assumption is that maximum and minimum temperatures occur at regular intervals. The high temperature occurs during afternoon hours and the minimum temperature around dawn. These assumptions may not be valid when using 24-hr temperatures from climatological observation stations. For example, the maximum 24-hr temperature may not have occurred during the afternoon hours. Likewise, the minimum temperature may have occurred at some hour other than dawn. These situations often occur when a weather front moves through a region, exchanging cold (warm) air for warm (cold) air

A second type of problem arises in the data due to time of observation. Data are recorded in climatological stations near 8:00 AM, 5:00 PM, or midnight local time. There are days when temperatures do not reach the preceding day's temperature at observation time. Thus, the recorded minimum (maximum) 24-hr temperature will have occurred at observation time on the preceding day. Although nothing can be done about the time of maximum and minimum temperature occurrence under natural conditions, using a 12-hr minimum (maximum) temperature will eliminate the time of observation problem.

\section{A method for representing the daily temperature wave}

If the time of maximum daily temperature is $2 \mathrm{hr}$ after solar noon and the shape of the temperature curve responds to the daytime solar cycle, the temperature wave from sunrise to sunset can be described by Eq [1]:

$$
\begin{aligned}
T(t)= & \left(T_{\max }-T_{\min }\right) \times \sin \\
& {[(\pi \times t) /(D L+4)]+T_{\min } }
\end{aligned}
$$

where $T(t)$ is temperature at time $t$ after sunrise; $\mathrm{T}_{\max }$ is maximum temperature; $\mathrm{T}_{\min }$ is the morning minimum temperature, and DL is daylength (in hours).

A second expression is needed to define nighttime cooling starting at sunset. Net radiational sunrise occurs $\approx 0.5 \mathrm{hr}$ after astronomical sunrise. (Outgoing radiation is not balanced by incoming solar radiation until this time.) Thus, minimum daily tempera- tures are reached near time of sunrise. Thermograph records for Clemson, S.C. were used with the assumption that minimum temperature occurs at sunrise to develop an expression (Eq. [2]) for nighttime cooling (Linvill, 1982):

$$
\begin{gathered}
\mathrm{T}(\mathrm{t})=\mathrm{Ts}-\left[\left(\mathrm{Ts}-\mathrm{T}_{\mathrm{min}}\right) /\right. \\
\quad \text { in }(24-\mathrm{DL})] \times \ln (\mathrm{t}),
\end{gathered}
$$

where $\mathrm{T}(\mathrm{t})$ is temperature at time $\mathrm{t}>1 \mathrm{hr}$ after sunset and Ts is the sunset temperature obtained from Eq. [1]. Other terms in this equation are as defined in Eq. [1].

Stuff and Dale (1973) published the following algorithm (Eq. [3]) to calculate daylength (DL) from the climatological day number (CD) and latitude (LA). Climatological day numbers are the same for a given calendar day every year. Days are numbered from 1 Mar. rather than 1 Jan. to avoid the 29 Feb. numbering problem in leap years. Months are numbered with March as 3, and daylength is in hours.

If month $<3$ then month $=$ month +12 $\mathrm{CD}=$ INTEGER $(30.6 \times$ month +

$$
\text { day of month - 91.3) }
$$

If the latitude is $\leq 40^{\circ}$, then $\mathrm{DL}=12.14+$ $3.34 \times \tan (\mathrm{LA}) \times \cos (0.0172 \times \mathrm{CD}$ $-1.95)$.

If the latitude is $>40^{\circ}$, then $\mathrm{DL}=12.25+$ $\left[\left(1.6164+1.7643 \times(\tan (\mathrm{LA})]^{2} \times \cos \right.\right.$ $(0.0172 \times C D-1.95)$.

\section{A method to calculate chilling hours}

Calculation of chilling hours $(\mathrm{CH})$ requires solving the above equations for time during which temperatures are less than a critical temperature. Solving Eq. [1] leads to

$$
\begin{aligned}
\mathrm{CH}= & {[(\mathrm{DL}+4) / \pi] \times \arcsin } \\
& {\left[\left(\mathrm{Tc}-\mathrm{T}_{\mathrm{min}}\right) /\left(\mathrm{T}_{\max }-\mathrm{T}_{\mathrm{min}}\right)\right], }
\end{aligned}
$$

which gives chilling hours from sunrise until the critical temperature $(\mathrm{Tc})$ is reached. To make into account chilling hours before sunset in the evening, the following test is used: If $\mathrm{CH}>4$, then $\mathrm{CH}=2 \times \mathrm{CH}-4$.

Nighttime chilling hours are determined from Eq. [2] as

$$
\begin{aligned}
\mathrm{CH}= & (24-\mathrm{DL})- \\
& \exp \left\{\left[(\mathrm{Tc}-\mathrm{Ts}) /\left(\mathrm{Ts}-\mathrm{T}_{\min }\right)\right]\right. \\
& \times \operatorname{In}(24-\mathrm{DL})\} .
\end{aligned}
$$

\section{A method to calculate chill units}

Determination of tree fruit chilling requirements has been based on accumulated chilling hours. A better measure, however, may be chill units (Richardson, 1984). Rather 
may be chill units (Richardson, 1984). Rather than assuming a step function for the chilling unit calculations, as proposed by Richardson, a sine function was determined from his chart along with cut-off points to simplify calculations:

$$
\begin{gathered}
\text { Temperature Range }\left({ }^{\circ} \mathrm{C}\right) \\
0<\mathrm{T} \leq 25 \\
25<\mathrm{T}
\end{gathered}
$$

$$
\begin{gathered}
\text { Chill Units } \\
0 \\
\sin [(2 \pi / 28) \times \mathrm{T}]
\end{gathered}
$$$$
-1
$$

These tests are made of each hour's temperature calculated from Eqs. [1] or [2] and summed for the time period to find total chill units.

\section{RESULTS AND DISCUSSION}

\section{Chilling hour calculations}

Chilling hours were calculated from Eqs. [4] and [5] using Clemson climatological data for the years 1969 to 1973 . Hygrothermograph records of temperature were used to determine number of hours each season during which temperature were < 7.1C (45F) (Kish, 1970, 1971, 1972, 1973).

Chilling hours accumulated over weekly increments were used for this study. In each year and over the entire period, the slope of the line relating thermograph-determined and modeled chilling hours is nearly 1:1 (Table 1). The intercept of the regression line is 5 $\mathrm{hr}$ or less in each year. Thus, chilling hours calculated from the model are close to chilling hours calculated from hygrothermograph charts. Similar results were obtained when we applied this technique to data from other locations in South Carolina.

Determination of chill hours from thermograph recordings is a time-consuming, manual operation, especially" when many locations must be followed through the season. There is sufficient precision in the method described above to make it useful in following the current season using only a simple maximum and minimum thermometer. The method is also useful for preparing climatologies of chill hours from historical daily maximum and minimum temperatures.

\section{Chill unit calculations}

From 1980 to 1984, a Temperature Function Integrator (Solid State Equipment Ltd.,

Table 1. Regression coefficients between predicted and weekly accumulated chilling hours recorded at Clemson, S.C. $\mathrm{Y}=\mathrm{b} 1 \times \mathrm{X}+$ b $0 .{ }^{2}$

\begin{tabular}{clrcc}
\hline \hline Year & $\mathrm{b} 1$ & $\mathrm{~b} 0$ & $r$ & $\mathrm{n}$ \\
\hline $1969-70$ & 0.94 & 4.51 & 0.98 & 20 \\
$1973-71$ & 1.06 & -2.58 & 0.95 & 21 \\
$1971-72$ & 0.99 & -5.02 & 0.96 & 21 \\
$1972-73$ & 0.95 & 0.99 & 0.97 & 21 \\
All years & 0.99 & -0.79 & 0.96 & 80 \\
\hline
\end{tabular}

\begin{tabular}{|c|c|c|c|c|c|c|}
\hline Model & Coefficient & $1980-81$ & 1981-82 & $1982-83$ & 1983-84 & 19/30-84 \\
\hline \multicolumn{7}{|c|}{ 12-hr minimum temperature } \\
\hline Sine-logarithmic & b1 & 0.98 & 0.84 & 1.11 & 1.11 & 1.0 \\
\hline & b0 & 5.98 & 17.12 & 7.20 & 0.91 & 6.7 \\
\hline & $r$ & 0.90 & 0.85 & 0.98 & 0.98 & 0.9 \\
\hline Richardson & b1 & 0.79 & 0.75 & 0.97 & 0.95 & 0.8 \\
\hline & bo & 11.88 & 18.36 & 7.85 & 5.14 & 9.6 \\
\hline & $r$ & 0.91 & 0.84 & 0.96 & 0.97 & 0.9 \\
\hline \multicolumn{7}{|c|}{ 24-hr minimum temperature } \\
\hline \multirow[t]{3}{*}{ Sine-logarithmic } & b1 & 0.97 & 0.91 & 1.30 & 1.31 & 1.1 \\
\hline & bo & 5.17 & 11.91 & -6.96 & -15.56 & -2.0 \\
\hline & $r$ & 0.84 & 0.88 & 0.98 & 0.94 & 0.9 \\
\hline \multirow[t]{3}{*}{ Richardson } & b1 & 0.83 & 0.75 & 1.03 & 1.15 & 0.9 \\
\hline & b0 & 7.88 & 14.49 & 2.18 & -0.42 & 2.6 \\
\hline & $r$ & ก 87 & ก 84 & $\cap 08$ & $n$ or & $n 0$ \\
\hline
\end{tabular}

${ }^{2} \mathrm{Y}=$ recorded chilling hours, $\mathrm{X}=$ predicted chilling hours, $\mathrm{b} 1=$ slope of regression line, $\mathrm{b} 0$ $=$ intercept of regression line, $r=$ correlation coefficient, and $\mathrm{n}=$ number of cases.

Table 2. Regression coefficients between predicted and data logger measured chill units near Pontiac, S.C. $\mathrm{Y}=\mathrm{b} 1 \times \mathrm{X}+\mathrm{b} 0{ }^{2}$

${ }^{2} \mathrm{Y}=$ recorded chill units, $\mathrm{X}=$ predicted chill units, $\mathrm{b} 1=$ slope of regression line, $\mathrm{b} 0=$ intercept of regression line, $r=$ correlation coefficient, and $n=$ number of cases.

Lower Hutt, New Zealand) was used to record chill units in an experimental peach orchard near Pontiac, S.C. This data logger used a modified form of the Richardson relationships in its calculations.

Maximum and minimum temperatures from a nearby cooperative climatological weather station were used to calculate hourly chill units from Richardson's straight line approximation and by using Eqs. [1] and [2]. Both 24-hr minimum temperatures as recorded in the climatological record and 12-hr minimum temperatures corrected from hygrothermograph charts were used to calculate chill units.

The modeled chill units were totaled over the same time periods during which the Temperature Function Integrator data were recorded. These periods ranged in length from 4 to 14 days. A summary of the regression statistics for each model is contained in Table 2 ,

When Richardson's model using the 12hr minimum temperatures was correlated with the Temperature Function Integrator chill units, the short-period $r$ values for yearly regressions were between 0.84 and 0.97 , with a 4-year overall $r$ of 0.96 . The slope of the regression line varied from 0.75 to 0.95 , with the overall 4 -year slope of 0.88 . When the 24-hr minimum temperatures were used, the slope over the 4-year time period was 0.94 and $\mathrm{r}$ was 0.96

The $r$ values over the 4-year period when using the sine-logarithmic model described above are nearly the same. The slope of the regression, however, is near one (1.02) when the 12 -hr minimum temperature is used for calculations and 1.13 when the $24-\mathrm{hr}$ minimum temperature is used.

One objective of calculating chili units is to determine calendar dates on which specific chilling levels have accumulated. Thus, rather than looking only at the goodness-offit of weekly chill unit totals, it is necessary to see how each model estimates the data logger value as the chilling season draws to a close. In South Carolina, the chilling season usually comes to an end during February. The average absolute errors during the 4-year test period between Temperature
Function Integrator and model chill units on 1 and 15 Feb. are contained in Table 3.

Although the model using 12-hr minimum temperatures was best for short-period estimations of chill units, accumulated error through the season is less for the model using 24-hr minimum temperatures. About 78 chill units accumulate per week during mid-February in the Pontiac, S. C., area. Thus, the sine-logarithmic model using 24-hr minimum temperatures is in error by $\approx 3$ calendar days. The same model using 12-hr minimum temperatures is in error by nearly 1 week. In the Richardson model, either case is in error by some 4 to 5 days.

An Omnidata Chill Unit and Degree Hour Accumulator (Omnidata International, Logan, Utah) was installed at the Pontiac site during Winter 1984-85, 1985-86, and 198788. This instrument also used a modified version of the Richardson Chill Unit model. Data were not read from the instrument as frequently during these years as in previous ones. Thus, detailed analysis of the model fit to the data cannot be carried out. During the mid-February period cited above, however, the difference between model estimated and recorded chill units was no more than 50 units in any of these years. This difference was similar to that recorded during previous years using the Temperature Function Integrator.

\section{SUMMARY AND CONCLUSIONS}

A sine-logarithmic approximation of the daily heating wave has been used to determine chilling hours and chill units through the season using maximum and minimum

Table 3. Mean absolute error between predicted chill units and data logger-measured chill units on two winter dates, 1980-84.

\begin{tabular}{rrrrrr}
\hline \hline & & \multicolumn{2}{c}{$\begin{array}{c}\text { Sine-logarithmic } \\
\text { model }\end{array}$} & \multicolumn{2}{c}{$\begin{array}{c}\text { Richardson } \\
\text { model }\end{array}$} \\
\cline { 2 - 6 } Date & & $12 \mathrm{hr}^{2}$ & $24 \mathrm{hr}$ & $12 \mathrm{hr}$ & $24 \mathrm{hr}$ \\
\hline \multicolumn{4}{c}{ Chill } & units \\
1 & Feb. & 75 & 38 & 40 & 53 \\
15 & Feb. & 84 & 47 & 52 & 65 \\
\hline
\end{tabular}

${ }^{2} \mathrm{hr}$ refers to time intervals during which the minimum temperature was observed. 
temperatures and daylength. Modeled values were compared with continuously measured values obtained with an on-site data logger. Considering the proximity of the measuring sites and the continuous calculations of the data logger, results using the sine-logarithmic model are an improvement over the straight-line methods proposed by Richardson. Also, the equations are easily incorporated into computer programs. Thus, these equations offer a convenient and sufficiently accurate method to follow chilling through the current season when only daily maximum and minimum temperatures are available. The absolute error between measured and calculated chill units results in an uncertainty window for date of total accumulation of $\approx 1$ week. This window is narrow enough to enable management decisions to be made using output from this model.

The equations provide a method of calculating chilling from historical weather data. Year-to-year comparison can be made and statistical probabilities for chilling accumulation determined from the historical data. Geographical areas can be compared to identify areas that have similar chilling climatologies, thereby improving the chance for successfully locating new growing areas for cold-requiring crops.
Two distinct uses for the equations have been described above. In both cases, the desired results were not exact hourly temperatures, but parameters related to them. In the first case, the results were hours below a critical temperature. Determining hours above a critical temperature is a trivial extension of the calculations. Time between specific temperatures can be found by solving the equations for each critical temperature and then subtracting the shorter time from the longer time. Chill units, an accumulated weighted temperature value, were calculated in the second case. The equations can be used easily with other temperature weighting factors to determine such values as hours of wet bulb temperature and growing degree hours.

\section{Literature Cited}

Eckersten, H. 1986. Simulated willow growth and transpiration: The effect of high and low resolution weather data. Agr. For. Met. 38:289306.

Kish, A. J., R.J. Ferree, and J.C. Purvis. 1970. Summary of 1969-70 South Carolina chilling hours. USDC/SCAE, Clemson Univ., Clemson, S.C. Agr. Weather Res. Ser. 24.

Kish, A.J. 1971. Summary of 1970-71 South Carolina chilling hours. USDC/SCAE, Clemson Univ., Clemson, S.C. Agr. Weather Res. Ser. 27.
Kish, A.J. 1972. Summary of 1971-72 South Carolina chilling hours. USDC/SCAE, Clemson Univ., Clemson, S.C. Agr. Weather Res. Ser. 31.

Kish, A.J. 1973. Summary of 1972-73 South Carolina chilling hours. USDC/SCAE, Clemson Univ., Clemson, S.C. Agr. Weather Res. Ser. 35.

Linvill, D.E. 1982. Chill hours and chill units from maximum and minimum temperature. Amer. Sot. Agr. Eng., St. Joseph, Mich. ASAE Paper 82-4510.

McCann, I.R. 1985. A soil temperature model for predicting the overwinering emergence of Heliothis zea and Heliothis virescens. PhD Diss., Texas A\&M Univ., College Station.

McFarland, J., I.R. McCann, and K.S. Kline. 1987. Temperature functions for insect growth and development. Amer. Soc. Agr. Eng., St. Joseph, Mich. ASAE Paper 87-1085.

Parton, W.J. and J.A. Logan. 1981. A model for diurnal variations in soil and air temperature. Agr. Met. 23:205-216.

Richardson, E. A., S.D. Seeley, and D.R. Walker. 1974. A model for estimating the completion of rest for' Red haven' and 'Elberta' peach trees. HortScience 9(4):331-332.

Stuff, R.G. and R.F. Dale. 1973. A simple method of calendar conversions in computer applications. Agr. Met. 12:441-442.

Sutton, O.G. 1953. Micrometcrology. McGrawHill, New York. 